\section{EMBRYRIDDLE \\ Aeronautical University}

SCHOLARLY COMMONS

\section{International Journal of Aviation,} Aeronautics, and Aerospace

\title{
Optimization and Analysis of an Elite Electric Propulsion System
}

\author{
Mehakveer Singh \\ Punjab Engineering College (Deemed to be University)., mehakveersingh11@gmail.com \\ Kapil Yadav \\ kapilyadav108@gmail.com \\ Satnam Singh \\ singhsatnam9046@gmail.com \\ Vikas Chumber \\ vikaschumber92@gmail.com \\ Harikrishna Chavhan \\ harichavhan2010@gmail.com
}

Follow this and additional works at: https://commons.erau.edu/ijaaa

Part of the Aeronautical Vehicles Commons, Propulsion and Power Commons, and the Systems Engineering and Multidisciplinary Design Optimization Commons

\section{Scholarly Commons Citation}

Singh, M., Yadav, K., Singh, S., Chumber, V., \& Chavhan, H. (2019). Optimization and Analysis of an Elite Electric Propulsion System. International Journal of Aviation, Aeronautics, and Aerospace, 6(5).

https://doi.org/10.15394/ijaaa.2019.1419

This Concept Paper is brought to you for free and open access by the Journals at Scholarly Commons. It has been accepted for inclusion in International Journal of Aviation, Aeronautics, and Aerospace by an authorized administrator of Scholarly Commons. For more information, please contact commons@erau.edu. 


\section{Introduction}

This paper is envisioned to serve the general impression of the modern technology of electric-based propulsion, its application, and scope. The aeronautics industries have been challenged to enhance efficiency, reduce noise, emission, and decrease dependency on carbon-based fuel aircraft. The aircraft of the future will be simpler to operate and more capable than today's combustion engine due to a convergence of technologies, mainly Electric Propulsion (Rezende, Barros, \& Perez 2018). An aircraft propulsion technology is mainly depended on the use of petroleum-based internal combustion engines, in the form of either aviation turbine fuel or aviation gasoline. Despite their widespread adoption, these fossil fuels have an adverse effect on the environment, both in terms of pollutants such as Carbon Monoxide (CO), Nitrogen Oxides (NOX), and Unburnt Hydrocarbons (UHC), and in terms of greenhouse emissions, the principal of which is Carbon Dioxide (CO2) which is shown in Figure 1 (Hileman, Donohoo, \& Stratton 2010).

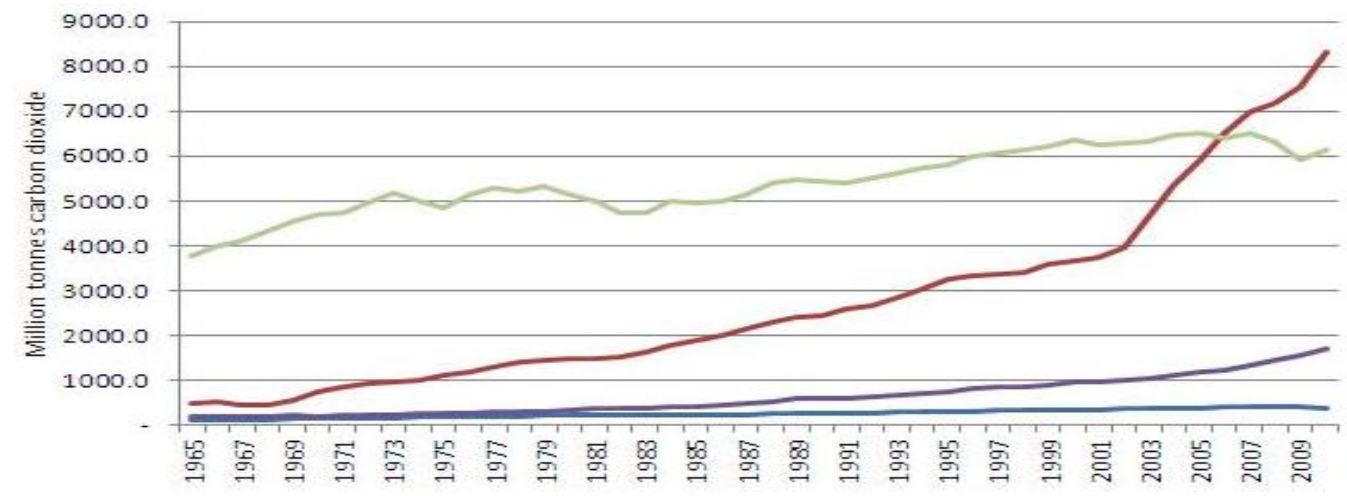

Figure 1. Variation in global temperature due to the harmful emission of gaseous from the aviation industry.

These problems can be diminished by using an alternative method of propulsion. The aerospace industry has experienced marvelous growth and success in all-electric powertrains and such concepts are being studied and even implemented on unmanned aerial vehicles and general aviation shown in Figure 2. One of the most promising is electric propulsion vehicles, in which electric energy is used to provide forward motion to aircraft. These systems can increase aircraft fuel economy, lower emissions, reduce takeoff and landing noise, increase system reliability, and improve operational capabilities(Kim, Perry, \& Ansell 2018). This work begins with an overview of the current aerospace sector, how they meet modern aerospace engineering challenges. 

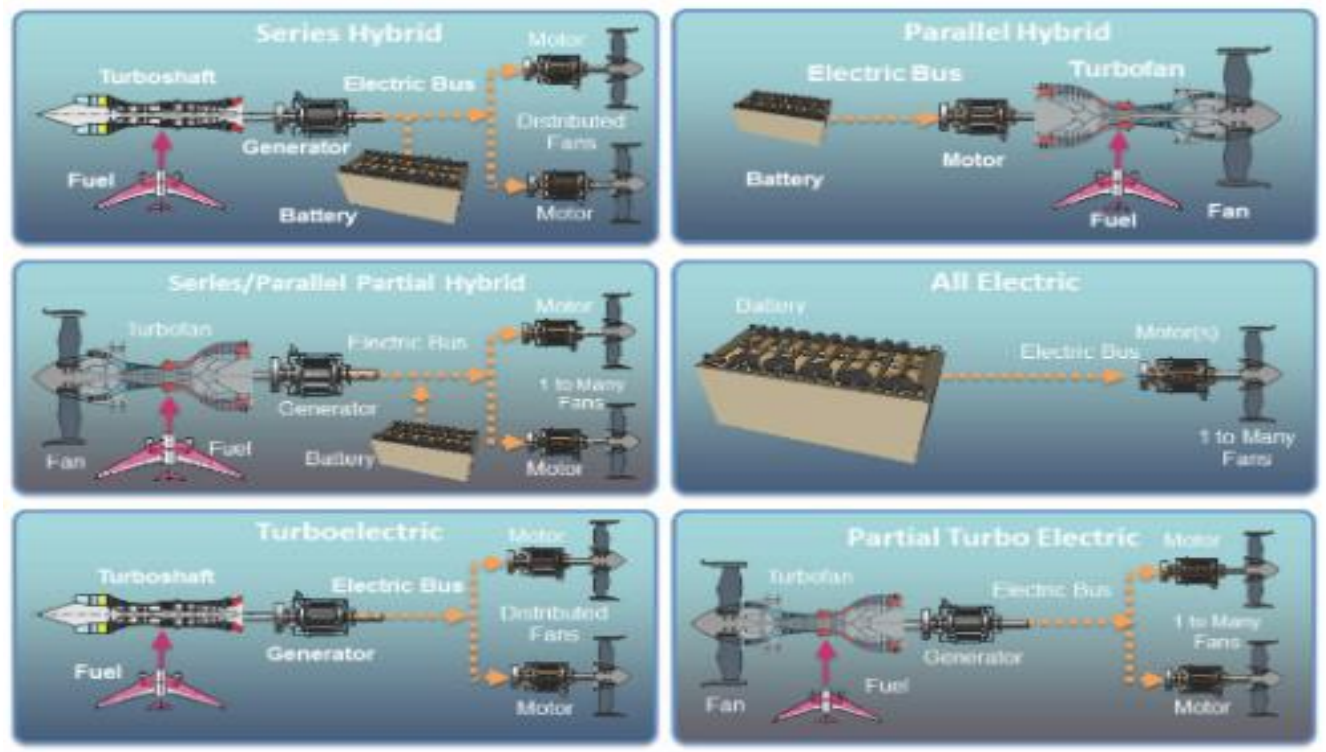

Figure 2. Several types of electric propulsion are under considerations (Committee on Propulsion and Energy Systems to Reduce Commericial Aviation Carbon Emmissions, 2016).

\section{Requirement of Electric Propulsion}

Diminishing the resources of fuel and aircraft transportation are responsible for creating maximum pollution in the cosmos. Aircraft propulsion system emissions, noise, safety, and performance are reshaping aerospace technologies. In the coming years, the requirement for transportation will create a surge in the aviation sector (Anon, 2007). Nowadays the aviation sector is a main fuel consumer; electric propulsion can reduce noise pollution and greenhouse effect that is created from current aircraft engines (Glassock et al. 2017). Moreover, general aviation alone consumed around 190 million gallons of aircraft fuel in 2015. A piston engine airplane uses around 13 gallons of fuel per hour. The electric-powered flight is working on battery technology to improve in terms of energy density and continues to improve at the same rate as it has over the past years(Curran et al. 2000). 


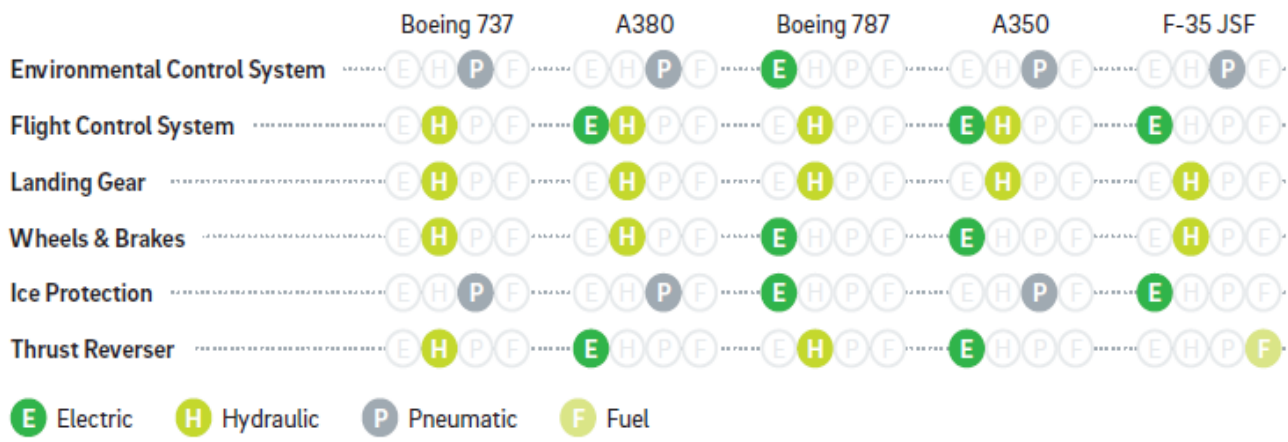

Figure 3. The different system in aircraft that operate on Electric, Hydraulic, Pneumatic, and Fuel sources as energy.

Electricity is required for multiple purposes in the aircraft. If reserachers are able to create surplus electrical energy in the electric-based aircraft, this surplus energy can be used to operate other mechanisms, such as hydraulic and pneumatic systems, thereby reducing aircraft weight. This is a major advantage of electric propulsion over conventional engines. Figure 3 represents the use of several systems based on electric in different aircraft. For example, the environment control system in (Boeing 787), flight control system in (A380, A350, F-35 JSF), ice protection in (Boeing 787, F-35 JSF), and thrust reverser in (A380, A350) are based on an electric source in different aircraft.

Figure 4 also depicts the surge in electric generating capacity which is used to operate several components. Commercial airlines followed the rapid changes toward the electric-based aircraft in comparison with military aircrafts(Thomson et al., 2017). Moreover, the Figure 5 illustrates the sveral tpyes of electric propulsion configuration . 


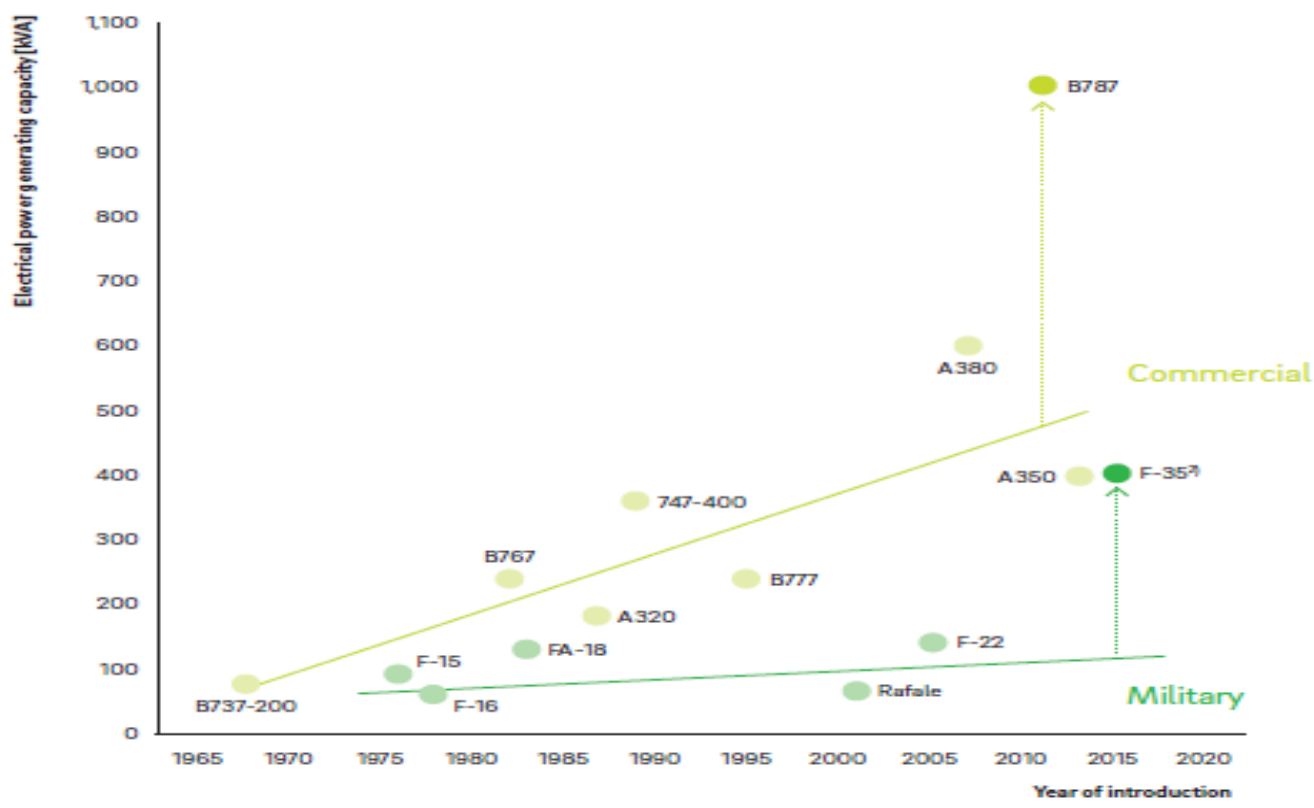

Figure 4. Enhancements in electrical power source in commercial and military aircraft.

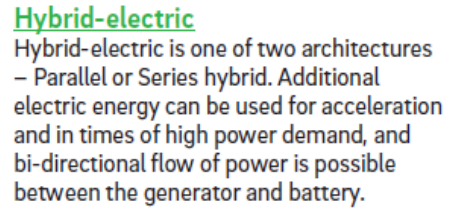

\section{Turbo-electric}

The kinetic energy of a turbo shaft is transformed into electric energy via a generator to drive multiple, distributed fans, with the fans driven by electric motors.

All electric

One, or multiple, fans are driven by electric motors with energy stored in a battery.

Source: NASA, Roland Berger

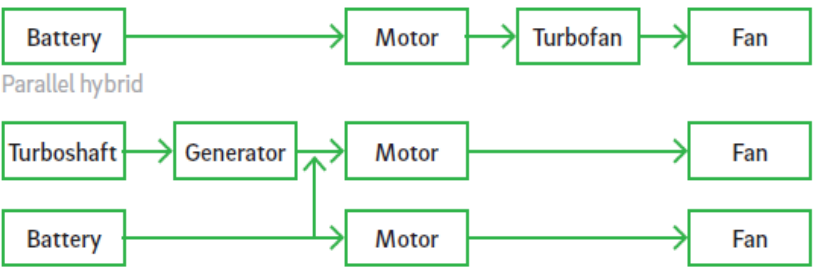

Series hybrid
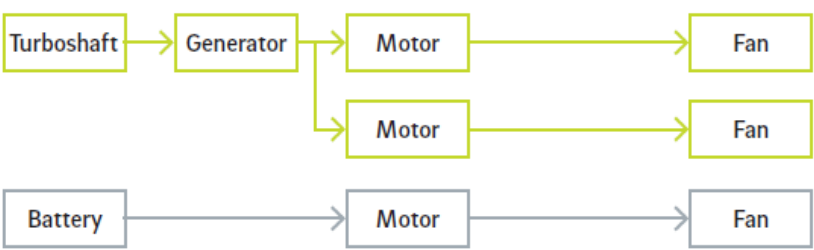

Figure 5. The schematic diagram of several types electric propulsion system (Friedrich \& Robertson 2015). 


\section{Turbofan Engines}

There are a plethora of performance parameters which are under consideration while manufacturing an engine, e.g., power to weight ratio and thermal efficiency. Moreover, an understanding of the general manufacturing and internal working of the engine is needed.

Figure 6 presents the engine which is mainly used for the commercial purpose, called a turbofan engine. The left section represents the inner section of engine by using the cut-section of CAD model. The right section represents the mounting of turbofan engine on a Boeing 787 aircraft (Yutko et al., 2018).
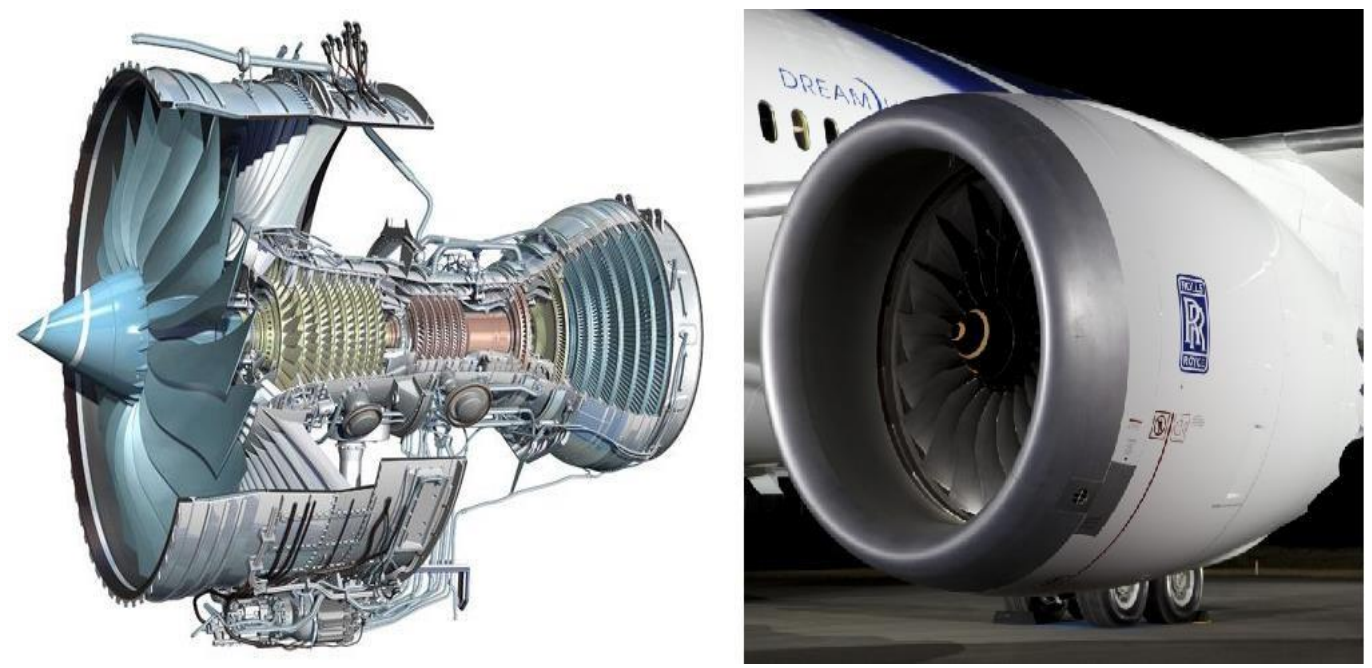

Figure 6. Rolls Royce turbofan engine sectioning (left) and it attached on a Boeing 787 aircraft (right).

In the turbofan engine, most of the propulsive force, approximately $80 \%$, is created by bypass ratio, in which air is moving from the bypass section of the turbofan engine. The remaining of the propulsive force is accelerated in the core of engine to turn the turbine and suction blade, which means, most engines attain $20 \%$ of thrust from the core of the engine (Dankanich \& Peters, 2017). The parameters of the turbofan engine which is shown in Table 1. The air mass flow in turbofan engines, while cruising, indicates propulsion efficiency. The thermal efficiency is one of majors when comparing two propulsion system. 
Table 1

Rolls Royce (Trent 1000 Engine) Performance Data

\begin{tabular}{|l|l|l|l|}
\hline Performance parameters & $\begin{array}{l}\text { Cruise velocity of aircraft }= \\
\text { Mach } \mathbf{0 . 8 5} \text { ) }\end{array}$ & $\begin{array}{l}\text { Take off velocity of } \\
\text { aircraft }=\mathbf{8 5 . 4} \mathbf{~ m} / \mathbf{s} \text { ) }\end{array}$ & Unit \\
\hline Thrust to weight ratio & $0.85: 1$ & $4.2: 1$ & - \\
\hline Thermal Efficiency (from LHV) & 50 & 40 & $\%$ \\
\hline Mechanical Power & 15.7 & 42.8 & $\mathrm{MW}$ \\
\hline Propulsive Efficiency & 77 & 47 & $\%$ \\
\hline Power to weight ratio & 2.65 & 7.47 & $\mathrm{~kW} / \mathrm{kg}$ \\
\hline Air Mass Flow & 315 & 1250 & $\mathrm{Kg} / \mathrm{s}$ \\
\hline Weight & 5,765 & & $\mathrm{~kg}$ \\
\hline Thrust & 47.9 & 238 & $\mathrm{kN}$ \\
\hline
\end{tabular}

\section{Electric Fan Engine}

The phenomenon on which electric fan engine is based is similar to turbofan engine, but rather than use combustion type engine to provide power for suction incoming by ducted fan, an electric motor is used for same work. There are mainly two difference in the configuration that ought to be considered (Bjarnholt 2016). In an Electric Fan Engine, the ducted fan is used to provide thrust to the flying object, compared to the air-breathing turbofan engine, which creates a small amount of the thrust force in the core of the turbofan engine. In addition, there are high-temperature benefits. An electric fan does not reach the extremely-high temperatures needed for a turbofan engine. Turbofan engines require a high melting point material or composite alloy where the jet engine reaches approximately 1500 to $1900 \mathrm{k}$ temperature, where the high strength material is required which have the capability to tolerate high temperatures. A highly efficient Electric Fan Engine model is shown in Figure 7, and the performance parameters are given below in Table 2. The small size of electric fan engine is used for comparison with a turbofan engine. 


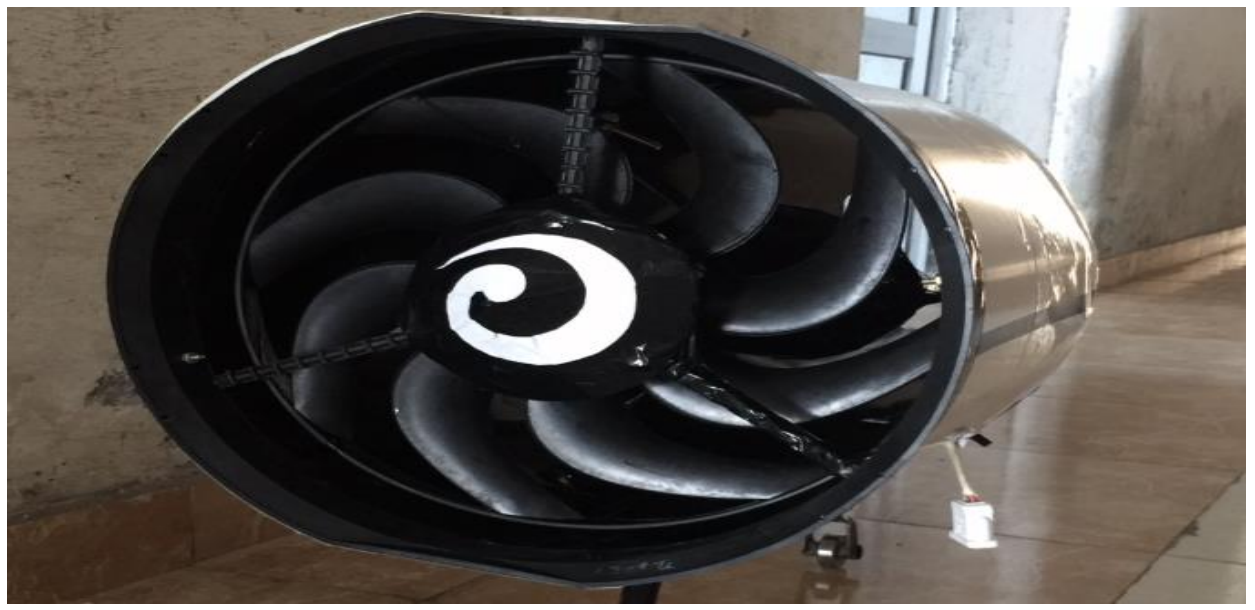

Figure 7. Highly efficient Electric fan engine (EFE) model.

Table 2

Performance Numbers for EFE Unit

\begin{tabular}{|c|c|c|}
\hline $\begin{array}{c}\text { Performance } \\
\text { metric }\end{array}$ & Value & Unit \\
\hline Static Thrust & $500-547.63$ & $\mathrm{~N}$ \\
\hline Weight & $8.7 \mathrm{~K}$ & $\mathrm{~g}$ \\
\hline Power & 92102 & $\mathrm{~J}$ \\
\hline $\begin{array}{c}\text { Thrust-to- } \\
\text { weight ratio, static }\end{array}$ & 6.20 & - \\
\hline
\end{tabular}

\section{Aircraft Flight Simulation Modeling (PIANO-X)}

Piano-X is a software using for aircraft analysis for instance range, emission calculation, performance, and many more specific parameters of aircraft. Performance parameters can be calculated with payload and range arrangement, if researchers are able to get full details about fuel consumption value of the particular flight. Most of the aircraft have been standardized using the finest available data of aircraft. This software is used for numerous purposes to study aircraft emission, 
optimization of flight and to study the fuel consumption of the aircraft which is useful for reference. See Figure 8 below.

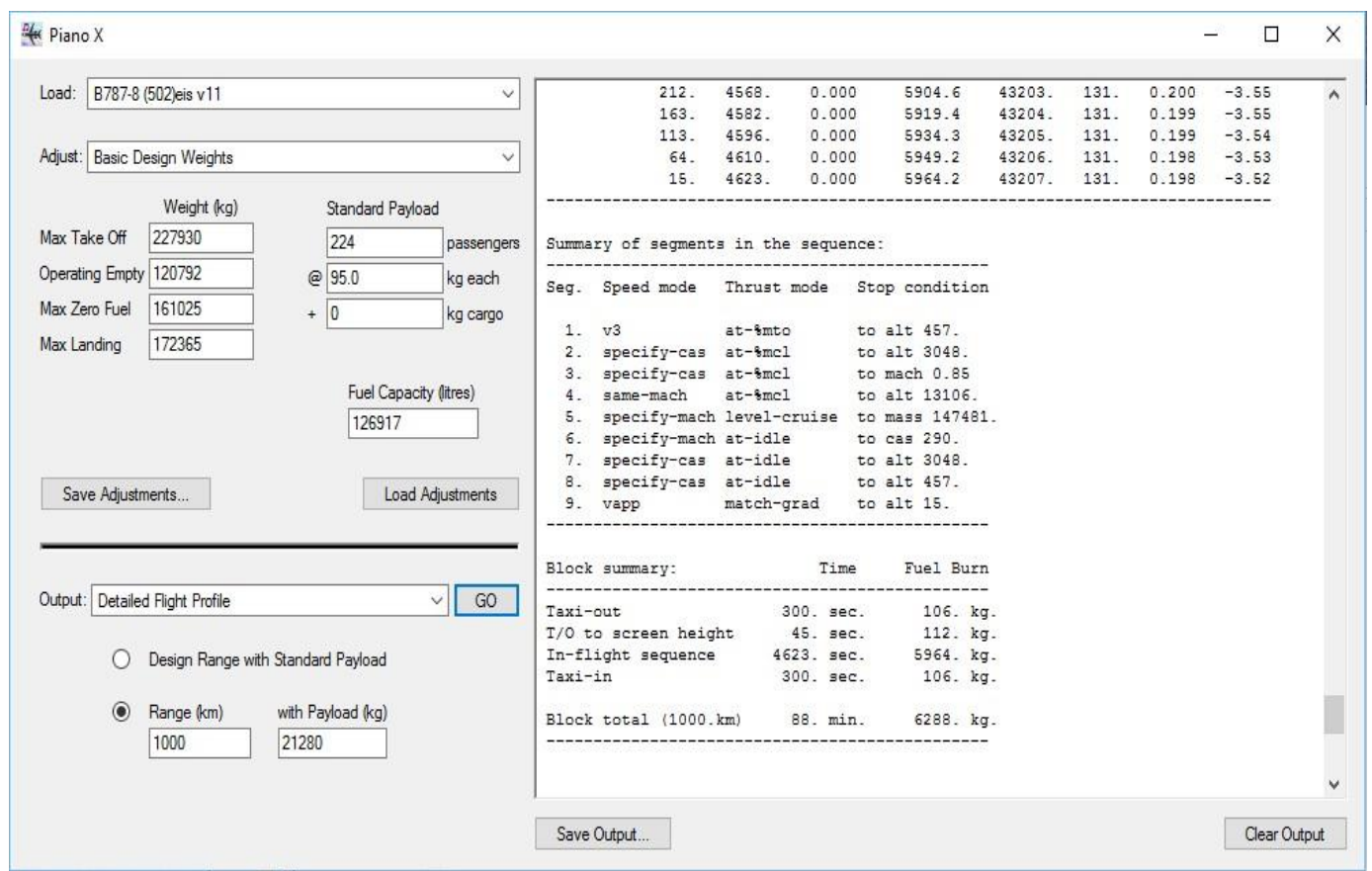

Figure 8. Piano-X, software which provides information about fuel burning, emission, and the brief information data about the performance of particular aircraft.

\section{The Electric Fan Engine}

An exclusive design of an electric design was under experimental investigation at MVS lab. This design will be used for commercial airlines in several years and have the potential to provide sufficient amount of thrust for aircraft mission. The Electric Fan Engine (EFE) is a new concept of the zerofueling propulsion system and the EFE configurations to meet the versatility and scalability requirement for fully-fledged aircraft. In either case, EFE distributed propulsion and power system are advantageous for longer range and endurance in comparison with other air propulsion devices. An Electric fan engine creates power without the need for fuel as in an air-breathing engine. The Electric fan engine produces around 123-pound thrust with the diameter of cowling is 11 inches, where the 747s aircraft thrust varies from 43000 to 63000 pound with the diameter of engine cowling at 8 feet 6 inches. Furthermore, 
testing on a blade configuration and mass flow rate passing frequency, harmonics, vibrations, and thickness of suction blade for a particular electric fan engine will be optimized soon. Higher-power motors can be used to rotate larger fans so that more thrust can be obtained. In EFE, it is expected to increase in thrust by change in suction blade configuration of blade. This new design shows considerable promise from using computational fluid dynamics methods.

\section{Conclusions \& Future Work}

This paper optimized the electric propulsion vehicle and the overall aim was to develop a design retrofit methodology with potential scale-up to medium and large transport aircraft. This new design will reduce the effect of harmful exhaust gases. Research regarding electric propulsion aircraft systems has largely focused on the power source. These systems must have the capability to survive in worst weather conditions. The specific energy of the batteries to overcome from these problems make it a versatile electric propulsion. The low operating costs of an electric airplane and the possibility to run it on $100 \%$ renewable energy, without any local pollution, is the strongest reasons to implement this technology in passenger flights. The Electric Propulsion project at MVS lab will demonstrate and fulfill the requirements of commercial aircraft as well as robotic and human exploration- systems highly efficient in the atmosphere. 


\section{References}

Anon. (2007). 1974 subject and author index. Nursing Forum, 13(4), 418-26.

Bjarnholt, P. (2016). Electric propulsion in passenger jet airplanes. Retreived from https://www.diva-portal.org/smash/get/diva2: 1115014/ FULLTEXT01.pdf

Curran, F., R., Myers, L., Rudolph, K., \& Wilbur, P. (2000). Electric propulsion for space systems. Retreived from http://www.stsci.edu/ jordan/other/ electric_propulsion_3.pdf

Dankanich, A., \& Peters, D. (2017). Turbofan engine bypass ratio as a function of thrust and fuel flow turbofan engine bypass ratio as a function of thrust and fuel flow compiled by Andrew Dankanich. Retreived from https://openscholarship.wustl.edu/cgi/viewcontent.cgi?article=1036\&conte $\mathrm{xt}=$ mems 500

Friedrich, C., \& Robertson, P. A. (2015). Hybrid-electric propulsion for aircraft. Journal of Aircraft, 52(1), 176-89.

Glassock, R., Galea, M., Williams, W., \& Glesk, T. (2017). Hybrid electric aircraft propulsion case study for skydiving mission. Aerospace, 4(3), 45.

Hileman, J. I., Donohoo, P. E., \& Stratton, R. W. (2010). Energy content and alternative jet fuel viability. Journal of Propulsion and Power, 26(6), 1184-96.

Kim, H. D., Perry, A. T., \& Ansell, P. J. (2018). A review of distributed electric propulsion concepts for air vehicle technology. Retreived from https://www1.grc.nasa.gov/wp-content/uploads/2018EATS-Review-ofDEP-Hyun-D.-6.2018-4998.pdf

Committee on Propulsion and Energy Systems to Reduce Commericial Aviation Carbon Emmissions. (2016). Commercial aircraft propulsion and energy systems research. Washington, DC: The National Academies Press.

Rezende, R. N., Barros, E., \& Perez, V. (2018). General aviation 2025 - A study for electric propulsion. https://doi.org/10.2514/6.2018-4900

Thomson, R., Sachdeva, N., Nazukin, M., \& Martinez, N. (2017). Aircraft electrical propulsion - The next chapter of aviation? Think: Act, 1-32.

Yutko, B., Titchener, N., Courtin, C., Lieu, M., Wirsing, L., Hall, D., . . . Church, C. (2018). Design and development of the D8 commercial transport concept. 31st Congress of the International Council of the Aeronautical 
Singh et al.: OPTIM IZATION AND ANALYSISOF AN ELITE ELECTRIC PROPULSION SYSTEM

Sciences. 